\title{
Thomas E. Brown, Quanjun Cui, William M. Mihalko, Khaled J. Saleh (eds): Expert consult arthritis and arthroplasty: the hip
}

\author{
Saunders Elsevier, Philadelphia, Hardbound, 448 pp, publication date: \\ June-2009, ISBN-13: 978-1-4160-4973-9, ISBN-10: 1-4160-4973-8, € 189.91
}

Pierre Kehr

Received: 16 August 2009 / Accepted: 18 August 2009 / Published online: 30 August 2009

(C) Springer-Verlag 2009

This work of more than 400 pages devoted to the surgery of the hip belongs to a new collection of five works entitled "Arthritis \& Arthroplasty". It gives a progress report on the state of the art in surgery of the hip; the preserving surgery, the arthroplasty of first intention, the miniinvasive techniques or about the surgery of recovery. The subjects of topical interest like the patching, the miniinvasive surgery or the femoro-acetabular conflict are studied in detail with richly illustrated color schemas and operative views.

The first chapters are devoted to the basic etiopathogenic concepts of the arthritis of hip, clinical evaluation, preoperative planning, materials and couples of friction... Then the arthroplasty of first intention is treated for various situations: femoral deformation, dysplasic hip, fracture of acetabulum...

The mini-invasive surgery is not forgotten and it described with six richly illustrated chapters. An important part of the work is devoted to the complications of the arthroplasty: inequality between the length of the lower extremities, complications neuro-vascular, infectious or peri-prosthetic fractures.
An inventory of lesions and solutions are proposed for each complication. Ten chapters are devoted to the recovery of the femoral slope or the acetabular slope. The following concepts are reviewed: cemented recovery, taken again without cement, technique of Exeter... with tricks and clever ways.

The bibliography is not exhaustive but sufficient and a suggestion of references selected by the author at the end of the chapter makes it possible to the reader to deepen his knowledge if he wishes it. Last, a certain number of video films are available on the DVD; included in the work but also "online" supplementing the text usefully.

This work is addressed more particularly not only to the orthopaedic surgeon specialists in the hip but also to the surgeons in formation or those who wish to improve their knowledge about surgery of the hip.

No funds were received in support of this study.

Laurent Galois Nancy
P. Kehr $(\square)$

ArgoSpine, Strasbourg, France

e-mail: kehrpier@aol.com 